Article

\title{
Research on Optimization and Design of Sustainable Urban Underground Logistics Network Framework
}

\author{
Hairui Wei ${ }^{1, * \mathbb{C}},{\text { Anlin } \mathrm{Li}^{1} \text { and Nana Jia }}^{2}$ \\ 1 Business School, University of Shanghai for Science and Technology, Shanghai 200093, China; \\ LIanlin0220@163.com \\ 2 Logistics Research Center, Shanghai Maritime University, Shanghai 201306, China; nnnajia@163.com \\ * Correspondence: weihairui2005@163.com
}

Received: 10 September 2020; Accepted: 31 October 2020; Published: 3 November 2020

\begin{abstract}
As a new mode of transportation, the underground logistics system (ULS) has become one of the solutions to the problems of environmental pollution and traffic congestion. Considering the environmental and economic factors in urban logistics, this paper conducts comprehensive design and optimization research on the network nodes and passages of urban underground logistics and proposes a relatively complete framework for a sustainable underground logistics network. A hybrid method is proposed, which includes the set cover model used to perform the first location of urban underground logistics nodes, the fuzzy clustering method applied to classify the located logistics nodes into the first-level and second-level nodes considering the congestion in different urban areas of the city and a mixed integer programming model proposed to optimize and design the underground logistics passage to find optimal passage parameters at every underground logistics node. Based on the above hybrid method, a sustainable underground logistics network framework including all-levels logistics nodes and passages is formed, with a subdistrict of Nanjing as a case study. The discussion of results shows that this underground logistics network framework proposal is very effective in reducing logistics time cost, exhaust emission and congestion cost. It provides support for decisions in the design and development of urban sustainable underground logistics networks.
\end{abstract}

Keywords: underground logistics; network optimization; fuzzy clustering method; integer programming model

\section{Introduction}

With the increasingly severe threat of climate change and resource depletion faced by human society, the demand for sustainable development is increasingly urgent [1,2]. Although the international definition of sustainable development is not uniform, it is currently focused on the following three aspects: sustainable development of the economy, environment and society. With the growth of urban population and the explosive growth of vehicle flow in urban logistics systems, climate change has become a huge burden on the urban healthy operation. The problems of congestion, emission, etc., are increasingly exposed [1]. The development of urban logistics systems is facing difficulties in the economic, environmental and social aspects.

In early 2020, when the novel coronavirus epidemic broke out in China, to cut off the transmission route of the highly contagious disease, the Chinese government lost no time in taking measures of intersection control and virus detection, and subsequently adopted the prevention and control measures of classified quarantine in various districts and regions. As the intersection control began, all vehicles were required to go through the procedures of temperature measurement by queuing at each highway entrance/exit before they could pass, which resulted in a congestion-caused long queue and, what is more, a huge inconvenience to the passage of freight vehicles. The hindering in 
the transportation and circulation of goods, such as vegetables and flowers, was intensified by the shortage of couriers and drivers during the epidemic; the express delivery industry, in which the urban distribution logistics for supermarkets and Chinese urban residents are highly vested, was fairly slow; and, in particular, the e-commerce and express delivery and distribution of fresh food even failed to meet the needs of customers. The pandemic has strongly impacted China's logistics industry, especially urban distribution logistics, which is excessively dependent on road transport, whose strong dependency on traffic smoothness and drivers leads to its failure in catering to people's livelihood needs in the event of an emergency. In addition, road-reliant freight transport would bring another two important problems:

Congestion has become an urgent problem, that threatens the sound urban operation in the present and future. About two-thirds of the 667 cities in China are stuck with traffic jams during rush hours, and in seaports like Shanghai and Shenzhen, traffic congestion is exacerbated by a higher proportion of road transport by container trucks heading to the port, which occupies a large number of urban roads. According to the statistics in 2015, Beijing's annual bill for traffic congestion amounted to 70 billion yuan ( $\$ 11.3$ billion).

What is more, the overuse of road transport also gives rise to air pollution. In particular, the contribution of road freight vehicles to urban air pollution is more significant, accounting for almost $50 \%$ of emissions [3]. Statistical data show that the pollutant emission of a heavy-duty truck is equivalent to that of 100 cars compliant with "China V" emission standards. More than $96 \%$ of NOx emissions are caused by trucks on busy urban roads.

It can be seen that the high proportion of road freight transport not only causes serious environmental problems, including urban congestion and pollution, but also counts against the assurance of urban logistics in the case of road control caused by accidents like the COVID-19 pandemic. However, the demand for road freight is still growing at a high speed, which will further aggravate its damage to the urban environment [4]. OECD (Organization for Economic Cooperation and Development) has carried out a project to forecast the global freight demand, whose results demonstrated that the global ground freight ton-kilometers (road and rail freight) will double from 2015 to 2030, especially in Asia, where they will increase 3.2 times, accounting for more than two-thirds of the global value $[5,6]$. China will have the largest and fastest-growing ground freight demand in Asia, as shown in Figure 1. In addition, China's e-commerce is in the stage of expansive development. By 2019, the number of urban express delivery in China has reached 63 billion and is still growing at a high speed of more than $20 \%$. The subsequent pressure on urban distribution is also increasing. To sum up, it is urgent to better plan future urban freight transport.

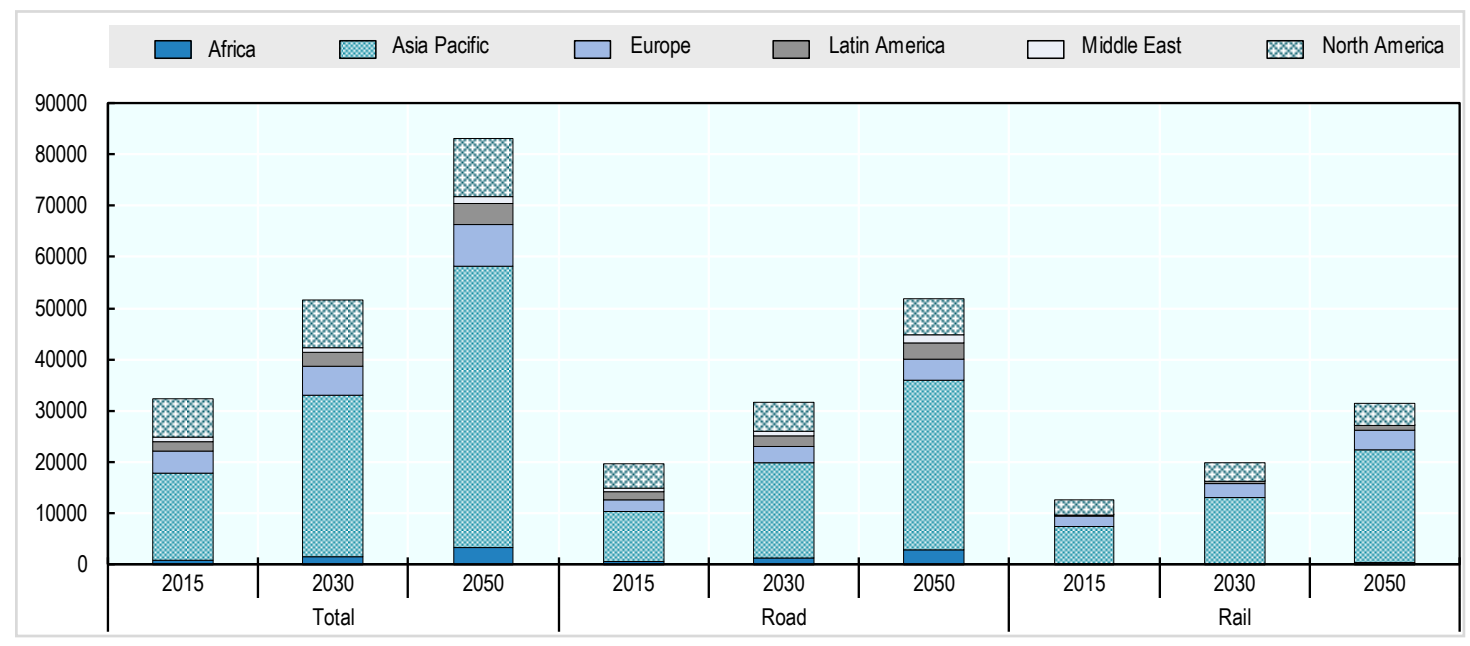

Figure 1. The growth of global freight ton-kilometers by region (billion ton-kilometers). Source: http://dx.doi.org/10.1787/888933442464. 
With such a background, more and more attention and research have been devoted to the sustainable development of supply chains and logistics, which are becoming hot and complex research fields [7]. The research and innovation of key core issues in practice, especially the integrated issues of economic, environmental and social performance, are getting more attention $[2,8]$. In the field of logistics, people began to try to explore new modes of transport to coordinate economic, environmental and social issues such as cost, time, emissions and congestion, in which the underground logistics system is the result. The ULS (underground logistics system) [3,9], also known as UFT (Underground Freight Transportation) or pipeline transportation system [5] (freight transport by underground pipeline, tube freight transportation, capsule freight pipelines) refers to the intracity and intercity logistics system which uses dual-model trucks and guided vehicles to transport goods through large-diameter underground pipelines or tunnels. As shown in Figure 2, JD.com, a well-known Chinese e-commerce and logistics company, proposes a concept of an underground urban distribution logistics system. As shown in Figure 2, underground intelligent hub stations are set up in different areas to connect capillary-like underground passages and cover nodes of underground logistics networks in certain areas. Furthermore, the stereoscopic lifting system is adopted to connect those nodes with the demand node of ground logistics, and the transport capsule is used to circulate goods in the underground pipeline. However, this concept is currently lacking a specific layout and planning, as well as the next step action.

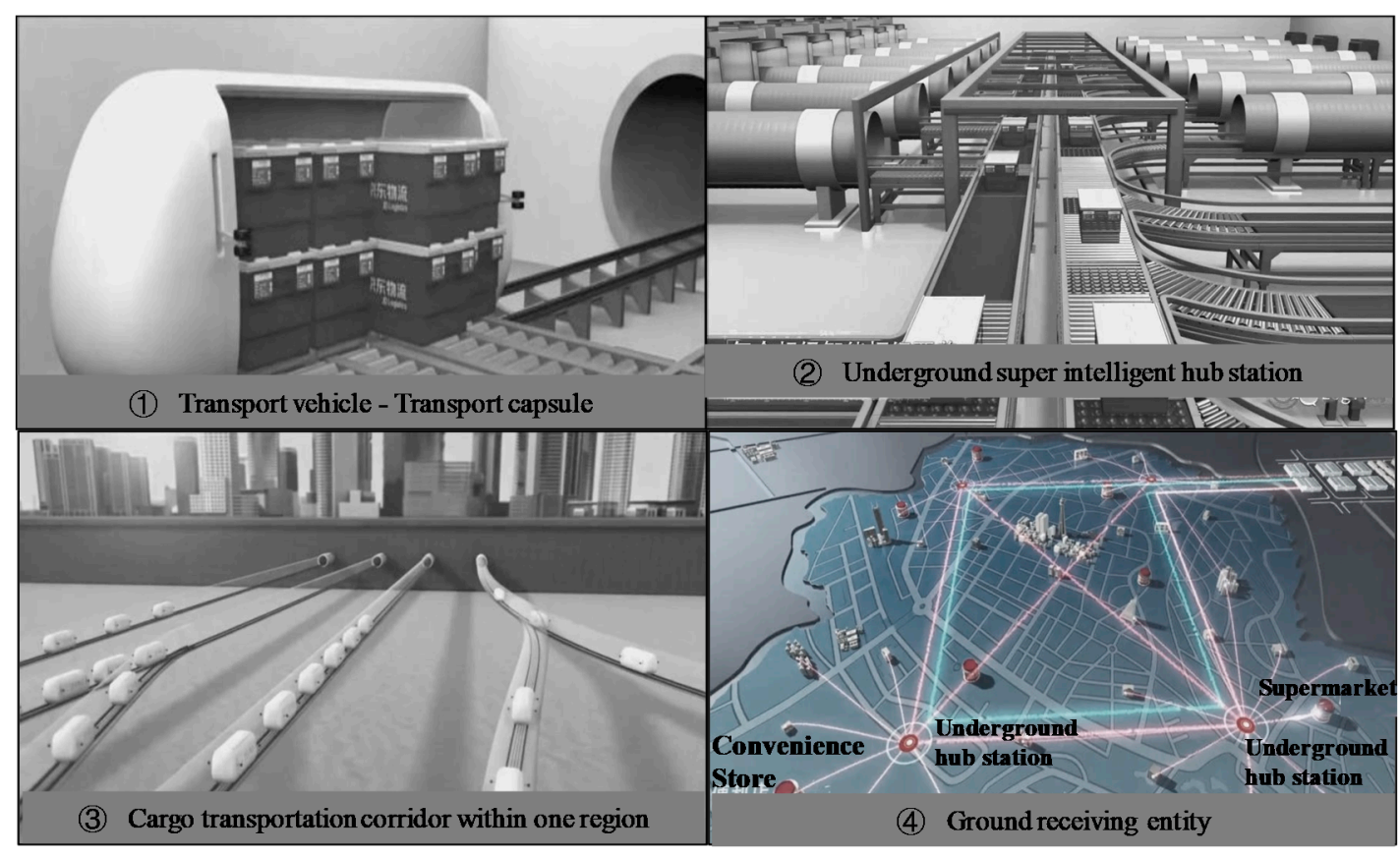

Figure 2. Intelligent Underground Logistics System of Jingdong Company in China. Source: http://adm.logclub.com/articleInfo/OTE5LTE1NDYzODk4NTk1NDk=.

The 20-plus-year study on the feasibility and socio-economic benefits of the underground logistics system since the beginning of the 1990s has proved that the underground logistics system can work as an alternative to modern modes of transport such as roadway, railway and waterway, since it can independently separate freight transportation and passenger transportation and is immune to the impacts of weather and other emergencies. Besides, it can also significantly protect the environment with low carbon, alleviate congestion and provide energy efficiency. Thus, it is an effective way to construct an urban sustainable logistics distribution system [10]. The feasibility study of the urban underground logistics network is presented in the construction of Xiong'an New Area, in China.

However, the current research is still mainly about the evaluation and feasibility of the underground logistics system and the analysis of the socio-economic benefits, while little research has been conducted 
on the optimization and design of the sustainable urban underground logistics network system framework considering the environmental and economic factors. The latter is important enough to determine the sustainable development of urban transportation logistics, especially during the outbreak of the pandemic, when the roads were closed. The question of how to make a reasonable layout to guarantee urban residents' and enterprises' demands for material circulation highlights the importance and urgency of a reasonable urban stereoscopic distribution network based on the underground logistics system.

Considering the environmental and economic factors in urban logistics, this paper conducts comprehensive design and optimization research on the network nodes and passages of urban underground logistics and proposes a relatively complete framework of sustainable underground logistics network. At first, this paper observes the congestion in different areas of the city, performs the first location of urban underground logistics nodes through the set cover model and classifies the located logistics nodes into first-level and second-level nodes via fuzzy clustering; secondly, for the purpose of the minimum construction and operation cost of underground logistics, this paper builds an optimization and design model of an underground logistics passage considering freight volume, congestion and other constraints on the located logistics nodes. Besides, an ant colony algorithm is used to solve the aforementioned model to design optimal passages for every underground logistics node, thus forming a sustainable underground logistics network framework including all-levels logistics nodes and passages. Finally, the effectiveness of the proposal is validated by analyzing and discussing the cases in a subdistrict of Nanjing. It provides support for decisions in the design and development of urban sustainable underground logistics networks.

\section{Literature Review}

Recent years have witnessed an economic boom, surging vehicles on the ground and consequently worse environmental pollution and urban traffic congestion, which seriously hampered urban development. Therefore, people look to pay more attention to the utilization of underground space. Such utilization in China is in the stage of networking where various underground facilities are gradually networking, such as underground shopping malls, rail transit, utility tunnels, etc. [11]. Based on the database of the Web of Science, Taylor and Francis, CNKI and so on, this paper analyzes the research literature in related fields, including the feasibility evaluation and impact of the ULS, the construction of the ULS and the ULS in an integrated transportation system and the planning of underground logistics system and network, based on the following literature review.

Despite the rapid growth of infrastructure construction in underground space in China, there is still a lack of systematic evaluation indicators to evaluate the development degree of underground space [12]. Some scholars began to create indicators for the development of underground space and evaluate the degree of underground space construction in various regions based on these indicators [13]. One of the proposals is the construction of the logistics of underground space. This logistics system, capable of storage and freight transportation, has been the solution of choice to ease the shortage of urban space and has attracted more attention in recent years due to its economic and environmentally friendly characteristics.

The underground logistics system (ULS) originated in England. In 1927, an underground transportation system was built by the Royal Mail in London. The priority of the research was how to deal with the massive transport volume and ease the traffic congestion. The early research on the underground logistics system mainly focused on the feasibility of this system. Sinfield proved the feasibility of the pipeline transportation system by calculating the cost of network construction in the actual urban environment [14]. However, Rijsenbrij proposed the creative combination of freight transportation with urban underground technology and analyzed the freight capacity of the underground [15]. Some scholars replaced the concept of supplementing logistics transportation with an idle underground transport capacity and evaluated the important indicators of underground stations through a complex network. They assessed the importance of each station via the TOPSIS model and 
located the candidate distribution hubs and stations [16]. Favoring other perspectives, some scholars investigated the economic advantages of electrically driven underground transportation over traditional transportation [9], while other scholars analyzed the quantitative relation between the implementation of the strategy of the urban rail transit system and the sustainability of urban transportation logistics in real-world simulations by means of system dynamics [3]. Moreover, the impact of the ULS from the perspective of the urban transportation system has been studied, for example, using highway toll data, traffic flow data and traffic survey data to build a model to calculate the emissions and the number of containers carried along the ULS from Waigaoqiao Port to the Jiading area [17].

From a macro-level perspective, scholars elaborated in 2017 on the policies of ULS construction and application in China with the aid of the PEST-SWOT model and offered some suggestions on its development [18]. The traditional logistics network has reached its limit in China's cities due to urban traffic congestion. Compared with traditional railways and special expressways, the underground logistics system has its unique edges, such as fast transportation and less impact on the environment and roads. As supporting technologies grow and mature, the future logistics system will gradually shift to underground logistics, producing an underground logistics network. The urban underground logistics system will become the new direction toward which urban logistics will evolve in the new century.

After the feasibility study, a large number of scholars have put forward their own insights on the construction of the underground logistics system. Firstly, based on the analysis of individual cases, Heijden summarized and analyzed the operational characteristics of different underground logistics networks, as well as their respective cost and efficiency, by analyzing specific cases, namely the Aalsmeer flower market and Schiphol Airport [19]. In order to cope with the increasing container transportation in the Port of Antwerp, scholars have established a special underground logistics system to solve the freight logistics problems on both sides of the port [9].

Secondly, as regards the intermodal transportation of containerized cargo, some scholars suggested establishing a port-convergence-station of underground logistics to connect underground logistics and the port. A robust optimization model is used to deal with the uncertainty of overruning limit flow, and a case study is employed to prove that the establishment of a port-convergence-station can ease the traffic jam [20]. Other scholars believed that in order to ensure the smooth connection between the underground and the container yard of the ground terminal in the underground container logistics system, an underground parking garage should be established to form a buffer zone for underground loading/unloading vehicles and underground guided vehicles (UGVs). The mixed-integer nonlinear programming model (MNIP) is used to build a model for the minimum waiting time of vehicles [21]. Several scholars created a two-stage model to realize road-underground-ocean container multimodal transport. The first stage is to determine the planning layout with the $0-1$ planning model, and the second stage is to build a simulation model under the current scenario to simulate the volume of goods that can be transported by transport containers within a specified time. They concluded that transportation efficiency can be improved in such a way [22]. In addition, considering the integrated transportation of roads and the ULS, Chen et al. established a mathematical model to study the freight transportation assignment problem in the integrated transportation network composed of aboveground roads and the ULS [23].

Finally, as for the planning of the whole urban underground logistics system, many scholars also contributed their own research methods. Some scholars designed the conceptual model of the underground logistics system with Cargo Cap as the carrier, advised pallet-size freight and carried out the network planning and terminal model design within certain areas [24]. Other scholars have carried out the network planning of underground logistics system by using the theories of the uncertain graph and dynamic programming [25]; when it comes to route selection, certain scholars used a genetic algorithm to plan the layout of the distribution route considering the time and investment [26]. Other scholars, taking into account the interests of both logistics planning decision-making departments and customers, used the bi-level programming model to study the location of logistics nodes in the construction of the underground logistics system [27]. Li and Wang took the Steiner minimal tree 
(SMT) as the theoretical model, based on the characteristics of the continuous expansion of large cities in China, and established an underground tree logistics network layout model for the expanding large cities in China [28]. They also optimized the algorithm by adopting the intelligence optimization algorithm using plant phototropism growth pattern as its heuristic criterion and created a plant growth simulation algorithm (PGSA). The algorithm uses the growth process of artificial plants in the space of a given logistics node set to find the optimal layout of the urban underground logistics network. In addition, some scholars located 23 imported grain distribution nodes through the qualitative method and evaluated the importance of each node in the freight railway, roadway, and waterway network by using complex network theory [29]. Some scholars use the improved Bat-inspired Algorithm to solve the $0-1$ mixed integer programming model, in order to locate the underground logistics center, which is faster than the basic Bat-inspired Algorithm [30].

After summarizing extensive relevant data, this paper establishes that many scholars' models only consider single factors, for instance, location of nodes or passages, but lack cost accounting and thus a comprehensive research. This paper starts from the location of nodes to the optimization of passages, considering factors including the node location, channel connection, specification selection and channel and node optimization in the later stage. Although the fuzzy clustering method is often used in the research for the evaluation of logistics enterprises or nodes [31], this paper employs it to classify the logistics nodes into first-level and second-level nodes, to in line with the reality, environmental protection and resource saving. Moreover, this paper elaborates on a case analysis in the Xianlin sub-district, in Nanjing, to carry out the test. Through this case, the whole analysis process is presented, and the conclusion is discussed and analyzed to show the feasibility of the approach employed in this paper.

\section{Research Method for the Network Design}

The comprehensive design and optimization methods for the sustainable urban underground logistics network proposed by this paper are shown in Figure 3, which contains three parts: the logistics nodes location, nodes classification and logistics passage design. The location of logistics nodes is the key to the whole underground logistics network, which determines the pattern and scale of the whole logistics network and directly affects the construction cost and the service level of the whole logistics system. However, considering that the number and location of the candidate nodes are unknown, and the logistics nodes need to be located to cover all freight logistics areas, this paper introduces congestion indexes to determine the areas to be covered and establishes a set cover model to determine the location of the nodes. In order to maximize resource savings, the nodes located above are further classified by the fuzzy clustering method, that is, by the classification of the first-level node and the second-level node. Then, a mixed integer programming model is proposed to optimize and design the logistics passage between nodes, and an ant colony algorithm is designed to solve this model. Based on these three parts, a complete sustainable urban underground logistics network can be constructed. Each area is included in the underground logistics network through the logistics nodes in that region. In this network, the first level-nodes are interconnected, while the second-level nodes are connected with the first-level nodes outside the area via the first-level nodes inside the area. Moreover, the first-level nodes can be connected with the logistics park and transfer cargo across areas. All the nodes are connected by the logistics passages designed above. 


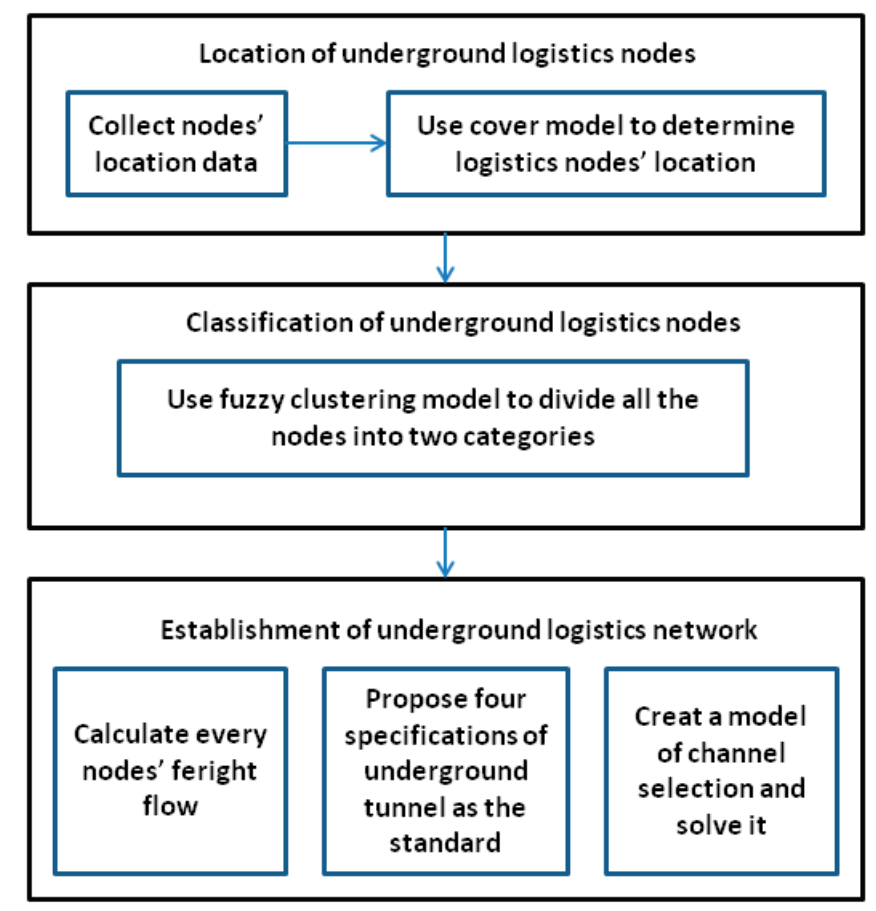

Figure 3. The flow chart of the establishment of underground logistics.

\subsection{Location of Underground Logistics Nodes Based on the Cover Model}

The Set Cover problem is a classical problem in combinatorial optimization and theoretical computer science. It requires a set to be covered with certain subsets at a minimum cost.

Let $N=\left\{e_{1}, e_{2}, e_{3}, \ldots e_{n}\right\}$ be $n$ areas; the complete set covering these $n$ areas is $S$, and $N$ nodes are set as $N=w \cup m \cup k \cup o \cup d$; where $w$ is the logistics park, $m$ stands for the first-level nodes of underground logistics, $k$ stands for the second-level nodes of underground logistics, $o$ is the supply location and $d$ is the demand location. Let $S_{1}, S_{2}, S_{3} \ldots S_{j}$ be one of the subsets of $N$; if $J \subseteq\{1,2,3 \ldots n\}$ and $\cup_{j \in J} S_{j}=S$, then $\left\{S_{j}\right\}_{j \in J}$ is called as a set cover of $N ; D_{i j}$ is the distance between nodes $i$ and $j ; B_{o j}$ is the set of logistics nodes $j$ that can serve demand point $o$, such that $B_{o j}=\left\{j \mid o \in S_{j}\right\}$, in order to find the minimum size of a set cover that can cover all congested areas after considering the realities of each region.

Given a decision variable $x_{j}$ for each $S_{j}(j=1,2,3, \ldots n)$ :

$$
x_{j}=\left\{\begin{array}{c}
1 \text { if } j \text { is located as the logistics node } \\
0 \text { if } j \text { is not located as the logistics node }
\end{array}\right.
$$

The $0-1$ model of the set cover problem can be formulated as follows:

$$
\begin{gathered}
\min _{j \in \mathrm{N}} x_{j} \\
\mathrm{D}_{i j} \leq 3, o \in B_{o j} \\
\sum_{e_{i} \in S_{j}} x_{j} \geq 1 \quad \exists j, \forall i=1,2, \ldots n \\
x_{j} \in\{0,1\}, j \in 1,2 \ldots n
\end{gathered}
$$

For the above functions, Function (1) states whether or not the $j$-th logistics node is selected. The objective Function (2) minimizes the number of facility nodes located as the objective of the model. Function (3) ensures that the radius of service from the $o$ point to the $d$ point is no more than $3 \mathrm{~km}$. 
Function (4) ensures that the area nodes $e_{i}$ in the set $S_{j}$ are covered by at least one set. The decision variable (5) refers to the demand nodes which are located as the facility nodes.

\subsection{Classification of Underground Logistics Node}

The set cover model can only locate the nodes which can cover all areas. But in practical applications, in order to maximize resource savings, nodes should be classified, and the cover model cannot classify these nodes into the different levels. This paper will divide nodes into two levels: the first-level nodes are interconnected with each other, while the second-level nodes are connected with the first-level nodes outside the area via the first-level nodes inside the area. The first-level nodes are connected with the logistics park and can transfer cargo across areas. In contrast, cluster analysis can classify research objects automatically under certain rules through mathematical methods. The traditional clustering analysis uses a hard classification approach to classify each research object, to be strictly identified into a certain class, which is an either-or analysis method with the classification decision boundary. However, in reality, most of the research objects have no boundary; instead, they have certain probability estimations. Hence, a soft classification approach, namely fuzzy clustering analysis, emerged.

\subsubsection{Fuzzy Clustering Analysis Model Building}

The purpose of fuzzy clustering analysis is to partition $n$ samples into $c$ clusters to minimize the sum of squared error (SSE) of mean value between each sample and its cluster. The basic method to obtain the minimum SSE is the $C$-means method. Therefore, this paper uses the fuzzy $C$-means clustering, whose model is formulated as follows:

Let sample set be $X=\left\{x_{1}, x_{2}, \ldots x_{j} \ldots x_{n}\right\}$ and the $i$-th cluster be $S_{i}(i=1,2, \ldots, c)$, while for element $x_{j}$, let $\omega_{i j}$ be a membership index, which means the degree of membership of elements $x_{j}$ belonging to the cluster $S_{i}$.

Assume that for a given integer $c(2 \leq c \leq j)$, it satisfies

$$
\begin{gathered}
\omega_{i j} \in[0,1], \forall i, j \\
\sum_{i=1}^{c} \omega_{i j}=1, \forall j \\
0<\sum_{j=1}^{n} \omega_{i j}<n, \forall i
\end{gathered}
$$

Then, the fuzzy matrix $W=\left[\omega_{i j}\right]_{c m}$ is a fuzzy C-partition, which is formulated as follows:

$$
M_{f_{c}}=\{\text { fuzzy } C-\text { partitions on all set of } \mathrm{X}\}
$$

Based on the above, the model of fuzzy $C$-means clustering analysis can be shown as follows:

$$
\begin{gathered}
\min z(W)=\sum_{i=1}^{c} \sum_{j=1}^{m}\left(\omega_{i j}\right)^{m}\left\|x_{j}-v_{i}\right\|^{2} \\
\text { s.t. } \quad v_{i}=\frac{\sum_{j=1}^{m}\left(\omega_{i j}\right)^{m} x_{j}}{\sum_{j=1}^{m}\left(\omega_{i j}\right)^{m}}, \forall i \\
W \in M_{f c}
\end{gathered}
$$


where $m$ is the number of sample indicators of $x_{j} ; v_{i}$ is the cluster centroid of the fuzzy C-partition of cluster $i$.

\subsubsection{Solution of the Fuzzy Clustering Model}

The fuzzy clustering model can be solved by many methods. In this paper, the fuzzy $C$-means clustering model is solved by using the method of the fuzzy equivalent matrix, as described below:

(1) Step 1: The standard deviation method is used to standardize the original data:

$$
u_{i k}^{\prime}=\frac{u_{i k}-\bar{u}_{k}}{\sigma_{k}}
$$

where $u_{i k}$ is the raw value of the $k$-th indicator of the sample $x_{i} ; \bar{u}_{k}$ is the average value of the $k$-th indicator, $\sigma_{k}$ is the standard deviation of the $k$-th indicator and $u^{\prime}{ }_{i k}$ is the standardized value of the $k$-th indicator of the sample $x_{i}$.

(2) Step 2: The fuzzy similarity matrix is formulated with the Euclidean distance method.

$$
\begin{gathered}
W=\left[\omega_{i j}\right]_{n \times m^{\prime}} \\
\omega_{i j}=1-\Gamma \sqrt{\sum_{k=1}^{m}\left(\boldsymbol{u}^{\prime}{ }_{i k}-\boldsymbol{u}^{\prime}{ }_{j k}\right)^{2}},
\end{gathered}
$$

where $m$ is the number of sample indicators; $\Gamma$ is a constant that can make sense; $0 \leq \omega_{i j} \leq 1, i$ and $j=1,2 \ldots n$ are the number of samples.

(3) Step 3: Based on the fuzzy similarity relation matrix, the fuzzy equivalent matrix can be solved. The max-min composition of relations is calculated for the fuzzy similarity relation matrix. The stopping criterion is $W^{\lambda}=W^{2 \lambda}$, and the fuzzy matrix satisfying the stopping criterion is the fuzzy equivalent matrix.

(4) Step 4: Setting the critical value of the cluster $\lambda$ in the fuzzy equivalent matrix, the samples can be clustered.

\subsection{Network Design of the Underground Passages}

The establishment of the underground logistics network requires underground passages to connect every node located by the method shown in Section 3.2. Therefore, the main work of this section is the establishment and optimization of underground passages for network nodes connecting. In this section, firstly, the assumptions and objectives of designing the passages among nodes are put forward. Secondly, the mixed integer programming model with a minimum total cost object for the optimal design of underground logistics passages is constructed. Finally, the solution method of the model is given. The details are as follows:

\subsubsection{Assumption on the Construction of the Passage Network}

Before building the model, this paper makes the following assumptions. First of all, the construction of the underground logistics system network should be located on the logistics network node located on Section 3; secondly, this paper proposes four specifications of underground tunnel available as the standard, which are: two-way four-track (10 tons), two-way double track (10 tons), two-way four-track ( 5 tons) and two-way double track ( 5 tons). The construction cost and transported vehicles vary with the types of tunnels. The goal of tunnel design is to meet the traffic capacity and minimize the logistics cost in the network. Thirdly, the logistics cost in this paper is composed of transportation cost and depreciation of underground logistics tunnels and nodes. Finally, because the freight in the underground nodes and passageways has to be daily cleared, those parts entering the underground must be transported to the demand location every day. Except for the underground passage from the 
logistic park to the first-level nodes, other underground passages admit underground transportation vehicles with a capacity of 5 tons. After considering the supply and demand between the nodes, the cargo-carrying capacity of vehicles and the road capacity, the location of first-level and second-level nodes should be adjusted appropriately to determine the tunnel route and build the underground logistics network.

\subsubsection{Model of Passage Network Design}

When constructing the underground passage, an important part of the logistics network, it is necessary to not only consider the freight flow between nodes and select the track with appropriate road capacity, but also examine the cost of different types of tracks. Aiming at the minimum cost, on the basis of the underground logistics node group located in Section 3.1, the logistics passage is designed and the underground logistics network model is built.

Let $q_{i j}$ be the freight volume from node $i$ to node $j ; q_{i j 0}$ be the freight volume of ground transportation from node $i$ to node $j ; q_{i j 1}$ be the freight volume of underground transportation from node $i$ to node $j ; v n_{i j}$ be the number of vehicles dispatched from node $i$ to node $j$, where $n_{i} \notin o$, $i, j \in A ; f_{i}$ is the congestion index at node $i ; F$ be the maximum congestion coefficient; $g$ be the annual comprehensive depreciation rate; $T C_{i j}$ be the freight transportation cost per ton-kilometer from node $i$ to node $j$, in which $i, j \in A ; S Q_{i}$ is the cargo supply of node $i$, wherein $i \in o ; D Q_{i}$ be the cargo demand of node $i$, where $i \in d ; E X_{i}$ is the freight volume per transportation vehicle of node $i$, where $n_{i} \notin o \cup d$; $\psi_{i j}$ indicates the connection between node $i j$ and $H_{i j}^{p}$ indicates the type $p$ tunnel route selected from $i$ to $j$, where $i, j \in w \cup m \cup k ; C_{p}$ be the construction cost of different types of tunnel, where $p$ is $1,2,3,4$ to represent four types of track, namely a two-way four-track (10 tons), two-way double track (10 tons), two-way four rails (5 tons) and two-way double track ( 5 tons), respectively; $C_{5}, C_{6}$ be the construction cost of the first-level logistics nodes and the second-level nodes, respectively.

The model is formulated as follows:

$$
\begin{gathered}
\min f_{1}=\sum_{(i, j) \in A} \psi_{i j}\left(\sum_{(i, j) \in A} T C_{i j} \times q_{i j}\right)+\sum_{(i, j) \in A} g \times \psi_{i j}\left(\sum_{j \in m} C_{4} \times x_{j}+\sum_{j \in m} C_{5} \times x_{j}+\sum_{i, j \in w \cup m \cup k} C_{p} \times H_{i j}^{p}\right), \\
\sum_{n i \in o, n j \in d}\left(q_{i j 0}\right) \times\left(\frac{f}{\sum_{i \in o} q_{i j}}\right) \leq F, \\
\sum_{(\mathrm{i}, j) \in \mathrm{A}} q_{i j}=S Q_{i} \mathrm{n}_{i} \in o, \\
\sum_{(\mathrm{i}, j) \in \mathrm{A}} q_{i j}=D Q_{i} \mathrm{n}_{i} \in d, \\
q_{i j} \leq E X_{i j} \times v n_{i j} \forall(i, j) \in A, n_{i} n_{j} \notin o \cup d, \\
\psi_{i j}=\left\{\begin{array}{l}
1 \quad \text { Node } i \text { and } j \text { is connected } \\
0 \quad \text { Node } i \text { and } j \text { is disconnected }
\end{array}\right. \\
q_{i j} \leq \psi_{i j} M \text { M is a large positive number, } \\
q_{i j} \in N^{+} i j \in A,
\end{gathered}
$$

In the above formula, the objective Function (4-1) indicates the construction cost of the logistics network, including transportation cost $\sum_{(i, j) \in A} T C_{i j} \times q_{i j}$, the construction cost of node $\sum_{j \in m} C_{4} \times x_{j}+\sum_{j \in k} C_{5} \times x_{j}$ and the construction cost of the tunnel $\sum_{i, j \in w \cup m \cup k} H_{i j}^{p} \times C_{p}$, where the construction cost of the node and the tunnel is included in the total cost in the form of depreciation per day. The constraint (17) restricts the congestion in the area to control the freight volume of ground 
transportation. Constraints (18) and (19) specify the volume of goods in the supply location and the demand location to meet all demands; (20) restricts the volume of goods transported by the vehicles, which cannot exceed the carrying capacity of conveyance; and (21) restricts the freight flow between nodes and defines zero freight flow when the nodes are disconnected; (22) restricts the connection between different nodes; (23) defines the non-negativity of the decision variables.

\subsubsection{Solution to the Model of Passage Network Design}

Based on the above models and assumptions, this paper gives the following parameters: assume that the average transportation cost per ton-kilometer is kept at about 1 yuan/ton-km (including the depreciation of vehicles and equipment), independent of the tunnel size. The construction costs of the underground logistics tunnel and node is the following: the two-way four-track (two independent tracks) (10 tons) tunnels and nodes cost 500 million yuan $\mathrm{km}$, the two-way double track (two independent tracks) (10 tons) tunnels and nodes cost 400 million yuan $/ \mathrm{km}$, the two-way four-track (two independent tracks) (5 tons) tunnels and nodes cost 350 million yuan/km, the two-way double track (two independent tracks) (5 tons) tunnels and nodes cost 300 million yuan $/ \mathrm{km}$ and the construction cost of a first-level node and a second-level node is about 150 million and 100 million yuan, respectively; the design life of the passages and the node lasts 100 years, and the annual comprehensive depreciation rate is $1 \%$.

Since Section 3 locates four first-level nodes and nine s-level nodes, and has fixed the service range of these nodes, the first step of the solving process is to determine the connectivity between nodes according to the service range. According to the supply-demand relationship of regional nodes, combined with the idea of an ant colony algorithm, the shortest feasible path between nodes is obtained (the process shown in Figure 4). According to the freight flow between nodes, the freight flow of each route in the network is calculated. On the basis of the freight flow along the route and with the aim of the minimum cost, a suitable tunnel is built while the freight flow is met. The specific steps are as follows:

(1) Step1: Calculate first-level nodes and second-level nodes serving supply location $o$ and divide the area where the nodes are located.

(2) Step2: Define the connectivity between nodes by their area.

(3) Step3: Find the shortest path selection by the connectivity and the supply-demand relation between $o$ and $d$.

(4) Step4: If the freight flow from $o$ to $d$ passes path $L$, add up the part where the freight flow from $o$ to $d$ passes path $L$, and then the freight flow along each route is obtained through this cycle.

(5) Step 5: Solve the model based on freight logistics after meeting the constraints of road capacity and the vehicle's carrying capacity at minimum cost and obtain the final result. 


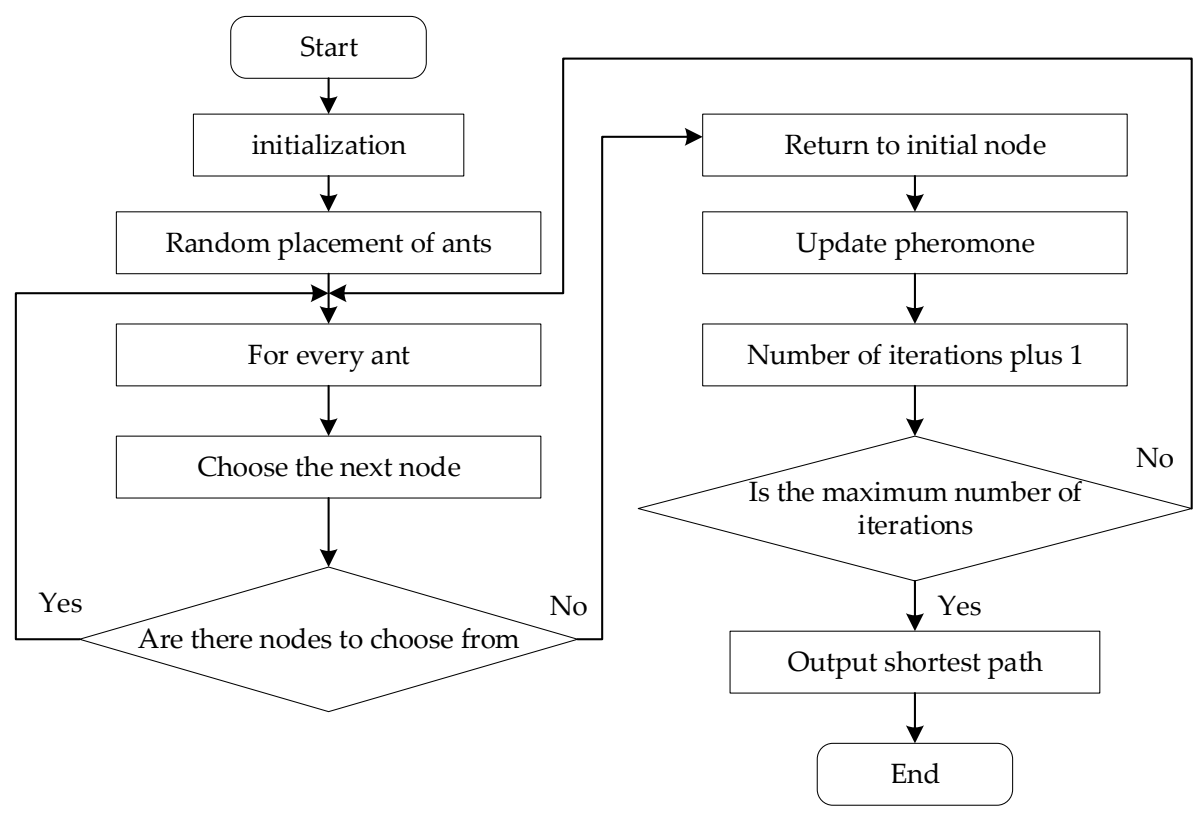

Figure 4. The flowchart for the shortest feasible path by the idea of an ant colony algorithm.

\section{Case Analysis}

\subsection{Data Source and the Set Cover Results}

This paper takes the freight transportation network of the Xianlin sub-district, in Nanjing, China, as a case to show the method and model proposed in Section 3. This paper quantifies the central points of each area on the coordinates and classifies these areas preliminarily. Among them, there are 4 logistics parks and 110 area nodes. Excluding the smooth traffic nodes, there are 107 congested area points. Therefore, let $n$ be 107, and the information of coordinates of each area is imported to mark all areas on the axis. As the 0-1 integer programming model is established in Section 3.1, the LINGO input model is used to locate logistics nodes, and a circle is drawn whose radius covers $3 \mathrm{~km}$ for service with the located node as the center to find the set cover, as shown in Figure 5:

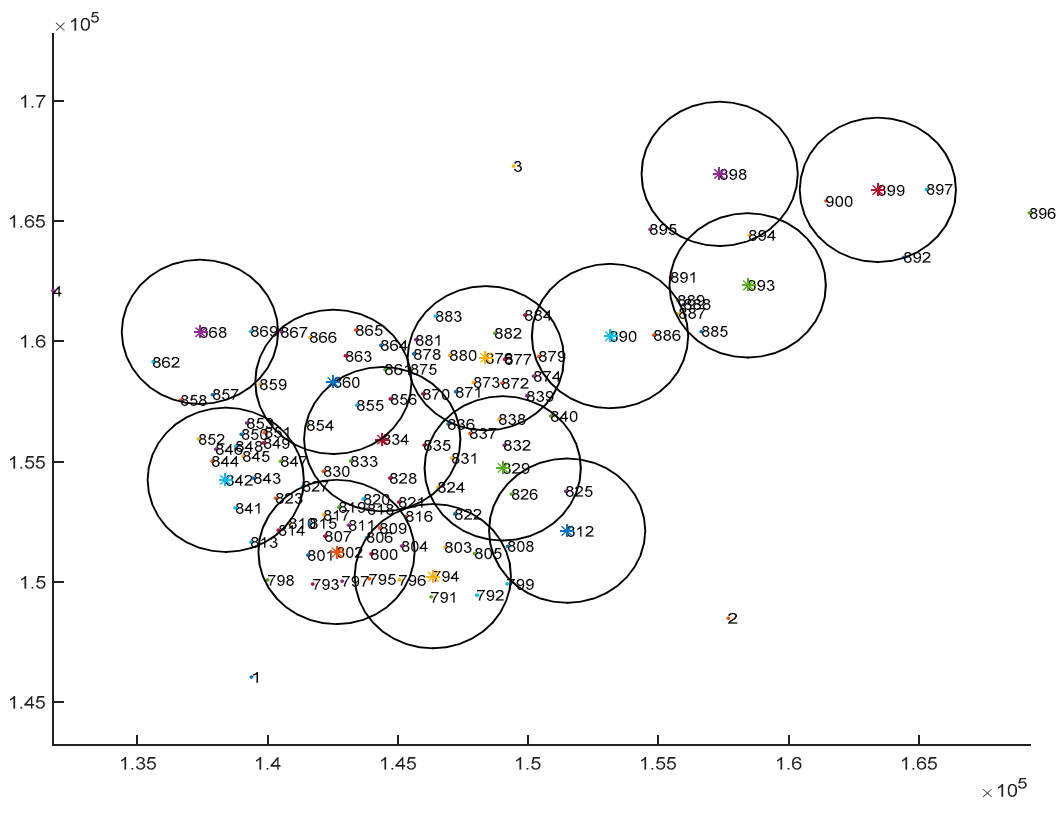

Figure 5. Centers and their set covering of area nodes. 
It can be shown from Figure 4 that if all congested areas (three of which are non-congested areas and require no coverage) are covered, a minimum of 13 circular areas with a radius of $3 \mathrm{~km}$ is needed, that is, 13 logistics nodes need to be located. The corresponding underground logistics nodes are [794, 802, 812, 829, 834, 842, 860, 868, 876, 890, 893, 898, 899], which are the minimum needs for nodes and are used as the candidate logistics nodes. The range of each node is shown in Table 1:

Table 1. Range of each node.

\begin{tabular}{cl}
\hline Selected Area Number & \multicolumn{1}{c}{ The Range of Each Node } \\
\hline 794 & 791792796799800803804805816 \\
$(146,343.98,150,237.09)$ & 793795797798801806807809810811814815817 \\
802 & 819 \\
$(142,646.6,151,242.96)$ & 808825826 \\
812 & 822824831832836837838840 \\
$(151,500.72,152,128.32)$ & 818820821828830833835856870 \\
829 & 813823827841843844845846847848849850851 \\
$(149,026.56,154,716.68)$ & 852853 \\
834 & 854855859861863864865867 \\
$(144,403.29,155,930.01)$ & 857858862869 \\
842 & 839871872873874875877878880881882883884 \\
$(138,393.68,154,240.89)$ & 879886887 \\
860 & 885888889891 \\
$(142,527.76,158,312.97)$ & 894 \\
868 & 892897900 \\
876 &
\end{tabular}

\subsection{Calculation of the Classification of Nodes}

In this paper, on the basis of the freight flow and congestion coefficient of each point, the area points are divided into four clusters, and four central points $(162,399.534,165,036.1616),(147,666.7922$, $152,209.9321),(140,382.8921,155,594.446),(150,628.9754,160,431.2199)$ can be obtained by cluster analysis. According to the principle of proximity, $[899,802,876,860]$ is located as the first-level node, shown in Figure 6.

Through cluster analysis, 13 candidate nodes are located, of which four are first-level nodes and nine are second-level nodes. The underground logistics node group and the range of nodes are shown in Figure 7: 


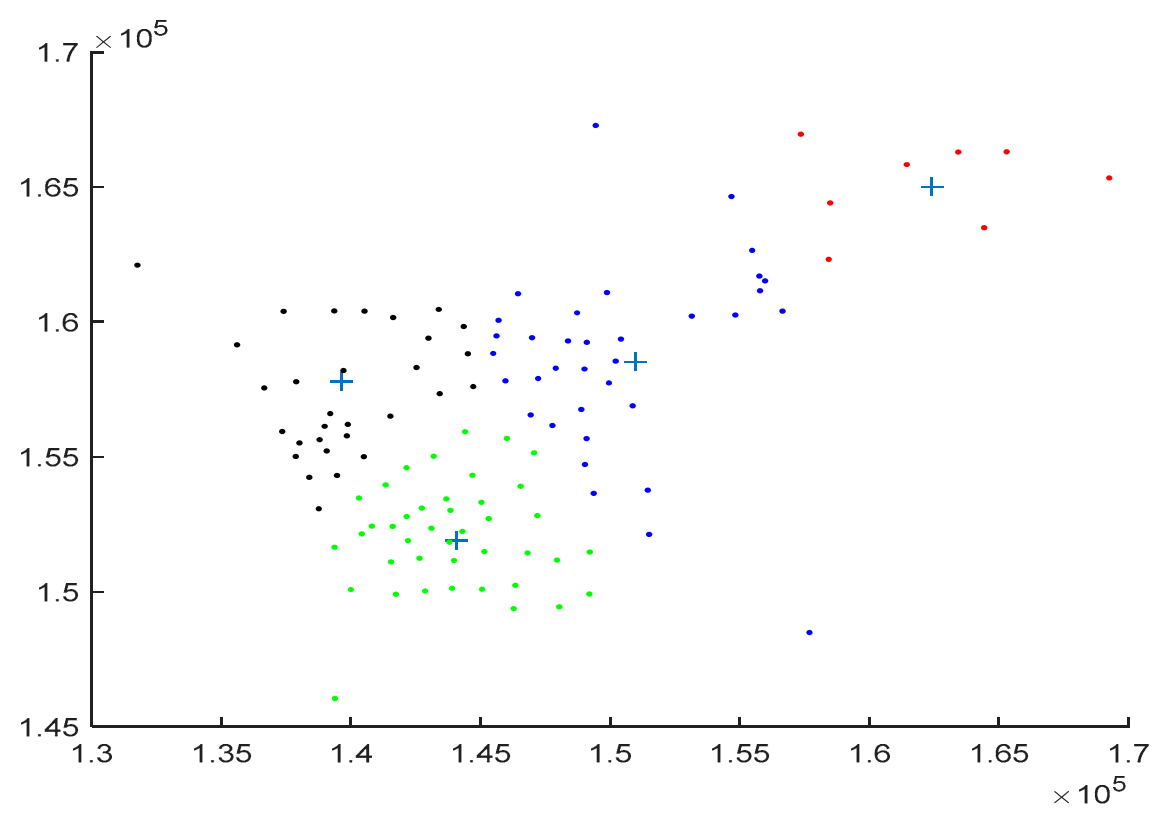

Figure 6. Chart of four cluster analysis.

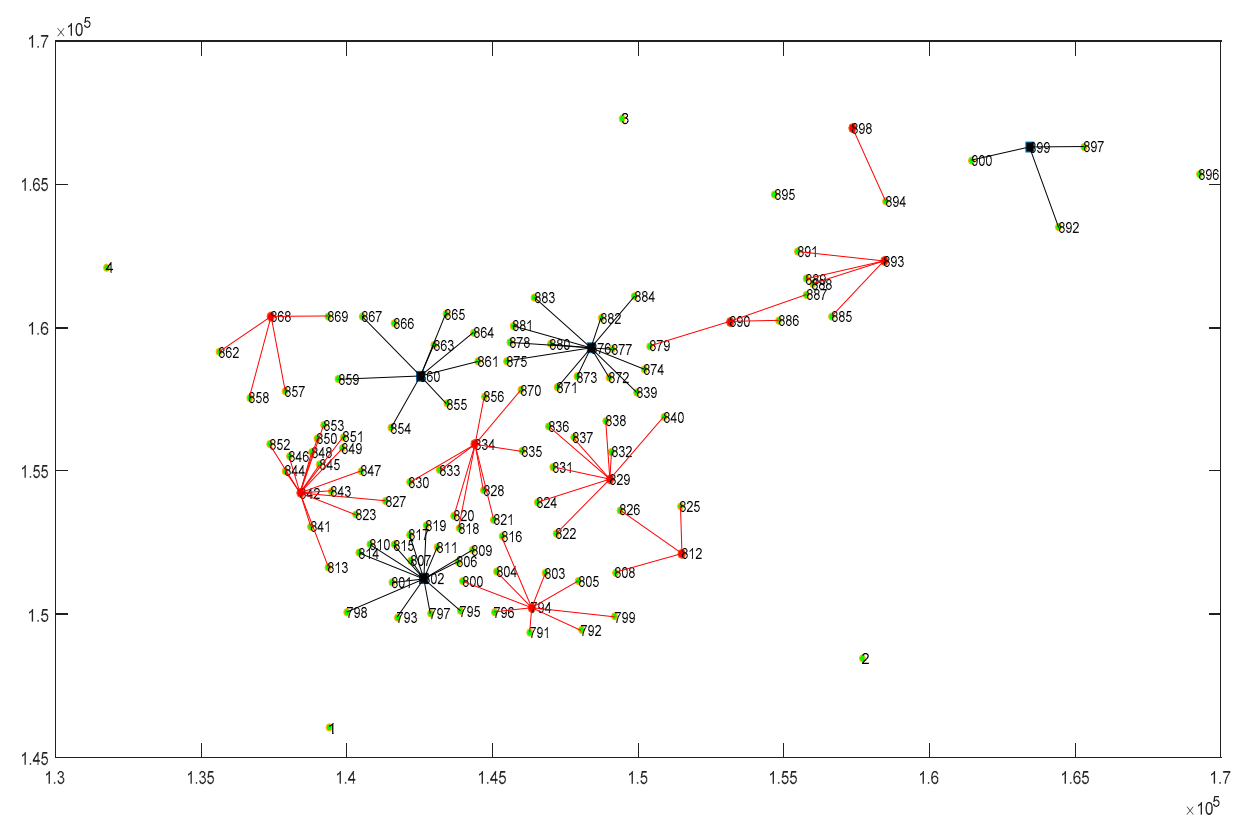

Figure 7. Range of logistics nodes.

\subsection{Calculation of Logistics Volume and Conversion Rate at Each Node}

In order to design the size of the passage, it is necessary to calculate the conversion rate of the logistics volume at each node. The calculation method is to calculate the freight flow through each node by selecting the range of each node and combining the OD flow between different areas, as shown in Table 2:

The transit rate of the first-level nodes $(\varphi)$ : the percentage of the freight volume transited from the logistics park to all other first-level nodes through the nearest first-level node and to the total shipment volume of the logistics park. It can be seen from Table 3 that the demand of the area covered by the first-level node 802 is 2998.225146 , while the freight volume sent by the logistics park to 802 is 7506.56 . Then, the transit rate $(\varphi)$ of node 802 is calculated to be 0.600585996 . It is same as the other nodes, and the results are shown in Table 3: 
Table 2. Actual freight flow of nodes.

\begin{tabular}{ccc}
\hline Type of Nodes & Nodes & Freight Flow \\
\hline \multirow{3}{*}{ First-level nodes } & 802 & $20,677.57$ \\
& 860 & $14,386.24$ \\
& 876 & $21,731.94$ \\
& 899 & $14,922.55$ \\
\hline \multirow{3}{*}{ Second-level nodes } & 893 & 2619.775 \\
& 898 & 1974.399 \\
& 834 & 7970.57 \\
& 794 & 4115.388 \\
& 829 & 6095.141 \\
& 890 & 3356.489 \\
& 812 & 3943.438 \\
& 868 & 2328.325 \\
& 842 & $10,284.56$ \\
\hline
\end{tabular}

Table 3. Transit rate of the first-level nodes.

\begin{tabular}{ccccc}
\hline Node & $\begin{array}{c}\text { Connected } \\
\text { First-Level Node }\end{array}$ & Total Feright Flow & Demand of the Area & Transit Rate \\
\hline 1 & 802 & 7506.56 & 2998.225146 & 0.600585996 \\
2 & 876 & 6894.007 & 1246.165567 & 0.819239294 \\
3 & 899 & 6574.985 & 2914.638985 & 0.556707873 \\
4 & 860 & 3377.313 & 1429.435132 & 0.576753739 \\
\hline
\end{tabular}

After running the program, the total cost of the network per day is 0.025920686 (100 million yuan). The freight flow on each route is calculated as shown in Table 4 (only the freight flow between $w, m$ and $k$ is listed on Table 4).

Table 4. Freight flow on the path between logistics nodes.

\begin{tabular}{cccc}
\hline Starting-Termination Nodes & Freight Flow & Starting-Termination Nodes & Feright Flow \\
\hline $1 \rightarrow 802$ & 7445.068 & $860 \rightarrow 4$ & 3145.795 \\
$2 \rightarrow 876$ & 6353.226 & $868 \rightarrow 842$ & 9.094293 \\
$3 \rightarrow 899$ & 6066.266 & $868 \rightarrow 860$ & 32.7123 \\
$4 \rightarrow 860$ & 3319.261 & $876 \rightarrow 890$ & 2721.026 \\
$794 \rightarrow 834$ & 0.509577 & $876 \rightarrow 802$ & 4904.947 \\
$802 \rightarrow 860$ & 5361.17 & $876 \rightarrow 860$ & 2780.502 \\
$802 \rightarrow 876$ & 5982.261 & $876 \rightarrow 829$ & 51.1532 \\
$802 \rightarrow 899$ & 2237.655 & $876 \rightarrow 812$ & 84.2354 \\
$802 \rightarrow 1$ & 7110.686 & $876 \rightarrow 899$ & 4767.379 \\
$812 \rightarrow 829$ & 0.901873 & $876 \rightarrow 2$ & 6072.739 \\
$812 \rightarrow 876$ & 50.7563 & $890 \rightarrow 812$ & 1.656738 \\
$812 \rightarrow 890$ & 2.3546 & $890 \rightarrow 829$ & 0.106358 \\
$829 \rightarrow 812$ & 0.751951 & $890 \rightarrow 876$ & $127,291.3754$ \\
$829 \rightarrow 876$ & 20.3576 & $893 \rightarrow 898$ & 1.222384 \\
$829 \rightarrow 890$ & 0.128422 & $893 \rightarrow 899$ & 8.2375 \\
$834 \rightarrow 794$ & 2.182539 & $898 \rightarrow 893$ & 0.543469 \\
$842 \rightarrow 868$ & 4.157621 & $898 \rightarrow 899$ & 6.1527 \\
$842 \rightarrow 860$ & 75.2342 & $899 \rightarrow 802$ & 2175.403 \\
$860 \rightarrow 802$ & 5068.836 & $899 \rightarrow 860$ & 1501.36 \\
$860 \rightarrow 842$ & 65.4271 & $899 \rightarrow 876$ & 4696.563 \\
$860 \rightarrow 868$ & 56.4893 & $899 \rightarrow 893$ & 10.6334 \\
$860 \rightarrow 876$ & 3018.422 & $899 \rightarrow 898$ & 8.3658 \\
$860 \rightarrow 899$ & 1506.653 & $899 \rightarrow 3$ & $133,094.4$ \\
\hline
\end{tabular}


According to the above freight flow table, the freight flow on the same route is added up, and the data is summarized. Combining that with the construction cost of different types of tunnels, the location and flow of tunnels at all levels and the actual flow of nodes are shown in Tables 5 and 6. In Table 5, the "Total freight flow" represents the freight flow in both directions. For example, the first line of "Total freight flow" is 14,555.75, which means all freight flow between node 1 and node 802, and it consisted in the freight flow of node 1 to node 802 and node 802 to node 1 . Moreover, the tunnel class represents different types of tunnels. In Table 6, the "Node freight flow" means the amount of freight flow that goes through each time period.

Table 5. Location and actual flow of tunnels at all levels.

\begin{tabular}{cccc}
\hline Starting-Termination Nodes & Total Feright Flow & Type of Tunnels & Tunnel Class \\
\hline $1 \rightarrow 802$ & $14,555.75$ & two-way four-track (10 tons) & 1 \\
$2 \rightarrow 876$ & $12,425.97$ & two-way double track (10 tons) & 2 \\
$3 \rightarrow 899$ & $139,160.7$ & two-way four-track (10 tons) & 1 \\
$4 \rightarrow 860$ & 6465.056 & two-way double track (10 tons) & 2 \\
$794 \rightarrow 802$ & 0.92314 & two-way double track (5 tons) & 4 \\
$794 \rightarrow 834$ & 2.692116 & two-way double track (5 tons) & 4 \\
$802 \rightarrow 834$ & 0.86321 & two-way double track (5 tons) & 4 \\
$802 \rightarrow 860$ & $10,430.01$ & two-way four-track (5 tons) & 3 \\
$802 \rightarrow 876$ & $10,887.21$ & two-way four-track (5 tons) & 3 \\
$802 \rightarrow 899$ & 4413.058 & two-way double track (5 tons) & 4 \\
$812 \rightarrow 829$ & 1.653824 & two-way double track (5 tons) & 4 \\
$812 \rightarrow 876$ & 134.9917 & two-way double track (5 tons) & 4 \\
$812 \rightarrow 890$ & 4.011338 & two-way double track (5 tons) & 4 \\
$829 \rightarrow 890$ & 0.23478 & two-way double track (5 tons) & 4 \\
$829 \rightarrow 876$ & 71.5108 & two-way double track (5 tons) & 4 \\
$842 \rightarrow 868$ & 13.25791 & two-way double track (5 tons) & 4 \\
$842 \rightarrow 860$ & 140.6613 & two-way double track (5 tons) & 4 \\
$860 \rightarrow 876$ & 5798.924 & two-way double track (5 tons) & 4 \\
$860 \rightarrow 899$ & 3008.013 & two-way double track (5 tons) & 4 \\
$868 \rightarrow 860$ & 89.2016 & two-way double track (5 tons) & 4 \\
$876 \rightarrow 890$ & $130,012.4$ & two-way double track (5 tons) & 4 \\
$876 \rightarrow 899$ & 9463.942 & two-way four-track (5 tons) & 3 \\
$890 \rightarrow 812$ & 4.011338 & two-way double track (5 tons) & 4 \\
$893 \rightarrow 898$ & 1.765853 & two-way double track (5 tons) & 4 \\
$893 \rightarrow 899$ & 18.8709 & two-way double track (5 tons) & 4 \\
$898 \rightarrow 899$ & 14.5185 & two-way double track (5 tons) & 4 \\
\hline
\end{tabular}

Table 6. Actual flow at each logistics node.

\begin{tabular}{cccc}
\hline Node & Node Freight Flow & Node & Node Freight Flow \\
\hline 1 & $14,555.75$ & 842 & 7803.591 \\
2 & $12,425.97$ & 860 & $40,827.54$ \\
3 & $11,869.29$ & 868 & 3348.457 \\
4 & 6465.055 & 876 & $54,542.94$ \\
794 & 2692.116 & 890 & 4786.365 \\
802 & $40,286.03$ & 893 & 3623.452 \\
812 & 4481.144 & 898 & 2238.17 \\
829 & 6711.271 & 899 & $34,612.4$ \\
834 & 1692.116 & & \\
\hline
\end{tabular}

By designing a logistics passage and logistics node, the overall framework of the underground logistics network in this area is shown in Figure 8: 


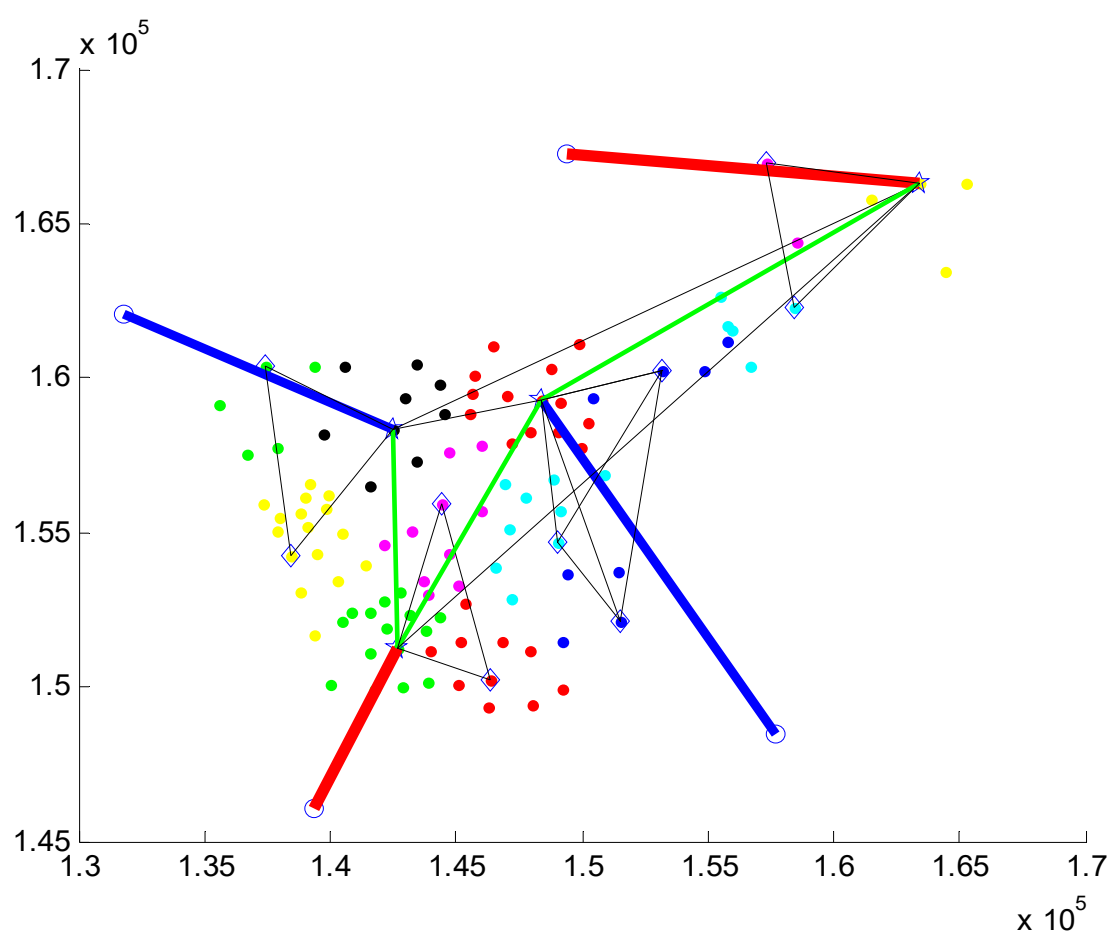

Figure 8. Framework of underground logistics network.

\subsection{Discussion of Results}

The underground logistics network system can effectively solve the problem of congestion caused by the ground transportation system and alleviate the emission of hazardous gases. Therefore, based on the underground logistics network planning of Xianlin district, Nanjing, concluded in the previous section, this paper analyzes and discusses the reduction in costs caused by traffic congestion and hazardous gas emission after the establishment of an underground logistics network system in this area. The results are as follows.

\subsubsection{Analysis of Exhaust Emissions from Underground Logistics Network}

Firstly, this paper calculates the exhaust emission during congestion. When a traffic jam happens, the vehicle runs at an idle or low speed, which still produces many exhaust gases. The measured comprehensive emission factors under an idle or low-speed driving state are higher than those on smooth traffic conditions. Therefore, the amount of vehicle exhaust emission is related to the length of the congested area and the emission factors of different gases. The specific calculation formula is as follows [32]:

$$
M_{c}=\left(A_{c}-A_{p}\right) \times S_{c},
$$

where $M_{c}$ is the total exhaust emissions, $A_{c}$ is the exhaust emission factor during congestion, $A_{p}$ is the exhaust emission factor on smooth traffic conditions and $S_{c}$ is the length of the congested road. Automobile exhaust includes two kinds of gases: greenhouse gas, namely $\mathrm{CO}_{2}$, and gas of air pollutants, mainly including NOx, $\mathrm{CO}$ and $\mathrm{HC}$. The comprehensive emission factors of various air pollutants are shown in the Table 7.

Table 7. Emission factors of various pollutants $(\mathrm{g} / \mathrm{kg})$.

\begin{tabular}{cccc}
\hline Exhaust Emission Factor & CO & HC & NOx \\
\hline$A_{c}$ & 33.2 & 14.24 & 28.0 \\
$A_{p}$ & 13.28 & 7.12 & 23.31 \\
\hline
\end{tabular}


The difference between the $\mathrm{CO}_{2}$ emission factors under congestion and smooth traffic conditions is about $293.82 \mathrm{~g} / \mathrm{km}$, assuming that the congestion rate between two nodes is 0.3 , that is, $30 \%$ of the road section will be under congestion. Meanwhile, we have also assumed that the average speed of vehicles under congestion is $20 \mathrm{~km} / \mathrm{h}$, while the average speed of vehicles under smooth traffic conditions is $30 \mathrm{~km} / \mathrm{h}$. Based on all values, the congested mileage between passages of each node was calculated, as well as the travel time under congestion. The specific results are shown in Table 8.

Table 8. Distance between nodes.

\begin{tabular}{ccccc}
\hline Starting Node & Ending Node & $\begin{array}{c}\text { Distance between } \\
\text { the Nodes }(\mathbf{m})\end{array}$ & $\begin{array}{c}\text { Congestion } \\
\text { Distance }(\mathbf{m})\end{array}$ & $\begin{array}{c}\text { Total Passage } \\
\text { Time (h) }\end{array}$ \\
\hline 1 & 802 & $24,092.13$ & 7227.64 & 0.92 \\
2 & 876 & 7119.71 & 2135.91 & 0.28 \\
$\ldots \ldots$ & $\ldots \ldots$ & $\ldots \ldots$ & $\ldots \ldots$ & $\ldots \ldots$ \\
899 & 898 & 6109.43 & 1832.83 & 0.23 \\
\hline
\end{tabular}

At last, according to formula (4-9), the additional exhaust emissions of Nanjing's Xianlin sub-district under congestion were calculated, as shown in Table 9.

Table 9. Additional emissions of various exhaust gases.

\begin{tabular}{ccccc}
\hline Exhaust Gas & $\mathbf{C O}_{2}$ & CO & HC & NOx \\
\hline $\begin{array}{c}\text { Additional } \\
\text { emissions }(\mathrm{kg})\end{array}$ & 7007.189 & 475.063 & 169.802 & 111.850 \\
\hline
\end{tabular}

According to the research results by Hai et al., after the construction of the ULS, the exhaust emissions of expressways in Shanghai's Waigaoqiao area, China, have been reduced by $16-28 \%$; and, at the same time, emissions on highways parallel to the ULS were reduced by $20-40 \%$ [17]. This paper calculates that the carbon emission of goods transportation in Xianlin area is about $8832.3 \mathrm{~kg}$ under normal conditions, and $6091.2 \mathrm{~kg}$ in the case of the ULS without congestion, which means that the carbon emission after the construction of the ULS is about $68.97 \%$ of that under normal conditions. The reduction level of carbon emission by ULS proposal in this paper is similar to Hai's research conclusion.

\subsubsection{Cost of Congestion Saved by an Underground Logistics Network}

This paper analyzes the cost of congestion saved by the underground logistics network system built in the previous section. The cost of congestion refers to the economic cost caused by ground traffic congestion. With the rapid increase of motor vehicles, traffic congestion has become increasingly prominent. Traffic congestion not only wastes the time of traffic participants but also results in additional energy consumption and environmental pollution. Therefore, this paper considers that the cost of congestion includes the cost of time, cost of fuel consumption and cost of exhausts [33]. This paper also calculates the cost of congestion of the underground logistics network system from these three factors.

$$
C_{s t}=C_{t}+C_{f}+C_{g}
$$

where $C_{s t}$ is the total cost of congestion, $C_{t}$ is the cost of time, $C_{f}$ is the cost of fuel and $C_{g}$ is the cost of exhaust gas treatment.

The first part is to calculate the cost of time. On the basis of the underground freight logistics network built in this paper, the cost of time is calculated by the time value of freight. This paper also cites the research of Yang and other scholars to calculate the time value of freight [32]. The cost of transportation time is mainly related to the transportation time. At the same time, the sensitivity of 
freight with different added value to time also varies. Therefore, the value of freight is highly correlated with the cost of transportation time. The specific formula is as follows:

$$
C_{t}=V_{F} \times \frac{\rho}{24} \times T,
$$

where $V_{F}$ is the value of the freight and $\rho$ is the sensitivity coefficient to time, which means the sensitivity of the freight to time. The larger the index, the more sensitive the freight to the time, and $T$ is the transportation time. For $V_{F}$, the daily value of freight is estimated by the freight volume mentioned above. Let the value of $\rho$ be $26 \%$ [33]. The result of the calculation indicates that the total cost of time taking place at the congested road section is 1,910,979.235 yuan.

The second part is to calculate the cost of motor vehicle fuel. Compared with smooth traffic, participation in traffic congestion will bring additional energy consumption, and this cost is related to the total mileage of the congested road section, the energy consumption coefficient of vehicles under congestion and smooth traffic condition, as well as the price of fuel per unit. The specific calculation formula is as follows [33]:

$$
C_{f}=\frac{S_{c}}{100} \times\left(V_{c}-V_{p}\right) \times Y_{f}
$$

where $S_{c}$ is the total mileage of congestion, $Y_{f}$ is the price of fuel, $V_{c}$ is the energy consumption index of motor vehicles under congestion and $V_{p}$ is the energy consumption index of vehicles under smooth traffic condition.

In the process of cost calculation, referring to the research of $\mathrm{Wu}$ and other scholars, this paper let the value of $V_{c}$ be $69.2(\mathrm{~L} / 100 \mathrm{~km})$, the value of $V_{p}$ be $51.56(\mathrm{~L} / 100 \mathrm{~km})$ and the value of $Y_{f}$ be 5.6 (yuan/L), and substituted the mileage of congestion of each section to calculate the cost of time in the underground logistics system. The final results show that the cost of fuel is $28,270.29$ yuan.

The third part is to calculate the cost of exhaust gas treatment. The analysis results found in the previous section indicate that, compared with the condition of smooth traffic, traffic congestion will make motor vehicles emit more exhaust gas, which mainly includes greenhouse gases and air pollutant gases. In this paper, the cost of treating such automobile exhaust is also included in the cost of congestion; and the cost is mainly related to exhaust gas emissions and the cost of exhaust gas treatment. The calculation formula of cost for air pollutant gas treatment is as follows [33]:

$$
C_{w}=p \times R \times \frac{M_{c}}{M_{s t}},
$$

where $R$ is the economic loss of air pollution from motor vehicles, $M_{s t}$ is the total emissions of air pollutant gases from society, $M_{c}$ is the air pollutant gas emission from additional congestion and $P$ is the proportion of pollutants from motor vehicles to total air pollutants. According to the formula, the cost of air pollutant gas treatment is 2145.433 yuan.

For the cost of greenhouse gas (namely $\mathrm{CO}_{2}$ ) treatment, this paper introduces the international carbon emissions trading price $Q$ to calculate the cost of greenhouse gas treatment. This paper let the international carbon emissions trading price be 18 US dollars/ton, and the specific calculation formula is as follows:

$$
C_{c}=M_{c o 2} \times Q,
$$

Finally, the cost of $\mathrm{CO}_{2}$ treatment is 882.956 yuan. After finding the treatment costs of greenhouse gas and air pollutant gas, respectively, the total cost of exhaust gas treatment is calculated by adding two costs, which are 3028.389 yuan.

$$
C_{g}=C_{w}+C_{c},
$$

Based on the above analysis results, this paper calculates that the total sum of freight transportation cost caused by congestion in the Xianlin sub-district, in Nanjing, is about 1,942,280 yuan. In other words, 
if the underground logistics network system is built, the above amount of cost of traffic congestion can be saved in each freight transportation cycle.

According to the research results by Liang et al., the cost of establishment of a complete underground logistics route is about 8.33 billion yuan [20], which seems to be a huge investment. However, if environmental costs such as congestion and emission and the cost savings of time are included, it will take about 12 years to offset the cost, which is equivalent to the investment recovery period of a highway and other huge logistics facilities. This shows that it is necessary and meaningful to consider the comprehensive benefits of environmental, economic and social costs when evaluating underground logistics systems.

\section{Conclusions}

In order to solve the problem of environmental pollution and transportation cost increase caused by urban traffic congestion, the underground logistics transportation system has been widely studied and discussed by scholars. This paper proposes a relatively complete systematic method for underground logistics nodes and structural components of passage logistics, designs the framework of sustainable urban underground logistics network considering environmental and economic factors and verifies the method by studying the Xianlin sub-district, in Nanjing, as an example. This paper first considers local congestion in different areas. With the help of a reasonable set cover model, the first urban underground logistics nodes are selected to locate 13 underground logistics nodes. Then, the located nodes are classified by the fuzzy clustering method to locate four first-level nodes and nine s-level nodes. Secondly, with the aim of the minimum cost of underground logistics construction and operation, with the constraints of traffic volume and congestion factored in, the optimization and design model of the underground logistics passage is constructed, and an ant colony algorithm is employed to solve the model, in order to find the optimal parameters for the passage at each node, thus forming a sustainable underground logistics network structure framework including all levels of logistics nodes and passages. Through the analysis of the underground logistics network structure in the Xianlin sub-district, in Nanjing, the underground logistics system built by following the method presented in this paper can effectively reduce the cost of urban traffic congestion and logistics emission pollution, and has good environmental and economic benefits.

This paper analyzes the cost of congestion and exhaust emission of the transportation system and draws the following conclusions:

First, in terms of exhaust emission reduction, greenhouse gas emissions are still more dominant than air pollutant gas emissions; however, only limited greenhouse gas emissions can be reduced by easing traffic congestion. In a freight transportation cycle, only about 7 tons of $\mathrm{CO}_{2}$ emissions can be reduced, while the reduction of $\mathrm{CO}, \mathrm{HC}$ and NOx amounts to about $0.1-0.5$ tons. Therefore, solving the problem of traffic congestion can alleviate exhaust gas emissions to a certain extent, but the effect is not significant. It is a more effective solution to replace the current truck with new energy vehicles or trains as the means of transport.

Second, when it comes to the reduction in the cost of congestion, the cost of time of freight accounts for the largest proportion of the total costs of congestion (nearly over $90 \%$ ), followed by costs of fuel, with the lowest proportion in exhaust treatment costs. Therefore, in the road section with large freight flow, establishing an underground logistics system for the purpose of reduction in freight time caused by traffic congestion is extremely effective, greatly cutting down the congestion-caused loss. In addition, the cost of fuel and exhaust treatment can also be cut by the underground logistics system, but the benefits generated from cost reduction are less than those obtained by the reduction in the cost of time. Hence, during the actual planning, all those cost reduction methods can be employed mainly in the section with large freight flow to obtain the maximum benefit.

Focusing on the three keywords economy, environment and society, which are related to the sustainable development of urban logistics, this paper puts forward an effective method and scheme for the construction of an integrated underground logistics system by grasping the core element of 
congestion alleviation, which provides a meaningful decision-making reference for the planning and construction of an underground logistics system in congested cities. However, there are also some research limitations. For example, this paper only considers the underground passage for freight transportation. However, with the fluctuation of the freight flow, the passage will either lay idle or require a queue. Therefore, the questions of how to calculate the cost of idling for the passage and whether it can be used for vehicles other than the specified ones should be considered, although they were not covered in this paper. In future research, the measures for an emergency in the underground logistics system will be studied to improve the research on the network.

Author Contributions: Data curation, A.L.; methodology, N.J.; writing—original draft, H.W. All authors have read and agreed to the published version of the manuscript.

Funding: This research was funded by [National Natural Science Foundation of China] grant number [71801150].

Acknowledgments: This work was supported by National Natural Science Foundation of China (No. 71801150). This support is gratefully acknowledged.

Conflicts of Interest: The authors declare no conflict of interest.

\section{References}

1. May, A.D. Urban transport and sustainability: The key challenges. Int. J. Sustain. Transp. 2013, 7, 170-185. [CrossRef]

2. Zimon, D.; Tyan, J.; Sroufe, R. Implementing Sustainable Supply Chain Management: Reactive, Cooperative, and Dynamic Models. Sustainability 2019, 11, 7227. [CrossRef]

3. Dong, J.; Xu, Y.; Hwang, B.; Ren, R.; Chen, Z. The Impact of Underground Logistics System on Urban Sustainable Development: A System Dynamics Approach. Sustainability 2019, 11, 1223. [CrossRef]

4. Richardson, B.C. Sustainable transport: Analysis frameworks. J. Transp. Geogr 2005, 13, 29-39. [CrossRef]

5. Visser Johan, G.S.N. The development of underground freight transport: An overview. Tunn. Undergr. Space Technol. 2018, 80, 123-127. [CrossRef]

6. OECD. ITF Transport Outlook; OECD: Paris, France, 2017.

7. Pagell, M.; Shevchenko, A. Why research in sustainable supply chain management should have no future. J. Supply Chain Manag. 2014, 50, 44-55. [CrossRef]

8. Fonseca, L.M.; Domingues, J.P.; Pereira, M.T.; Martins, F.F.; Zimon, D. Assessment of circular economy within Portuguese organizations. Sustainability 2018, 10, 2521. [CrossRef]

9. Vernimmen, B.; Dullaert, W.; Geens, E.; Notteboom, T.; T’Jollyn, B.; Van Gilsen, W.; Winkelmans, W. Underground logistics systems: A way to cope with growing internal container traffic in the port of antwerp? Transp. Plan. Technol. 2007, 30,391-416. [CrossRef]

10. Qian, Q. Urban sustainable development and development and utilization of underground space. Chin. J. Undergr. Space Eng. 1998, 18, 69.

11. You, X.; He, G.; Wang, Q.; Zhang, L. Current Status and Development Trend of Urban Underground Space in China. Tunn. Constr. 2019, 39, 173-188.

12. Kaliampakos, D.; Benardos, A.; Mavrikos, A. A review on the economics of underground space utilization. Tunn. Undergr. Space Technol. 2016, 55, 236-244. [CrossRef]

13. Chen, Z.-L.; Chen, J.-Y.; Liu, H.; Zhang, Z.-F. Present status and development trends of underground space in Chinese cities: Evaluation and analysis. Tunn. Undergr. Space Technol. 2018, 71, 253-270. [CrossRef]

14. Sinfield, J.V.; Einstein, H.H. Tunnel Construction Costs for Tube Transportation Systems. J. Constr. Eng. Manag. 1998, 124, 48-57. [CrossRef]

15. Rijsenbrij, B.J.C. The Potential of Metro Systems for City Logistics. In Proceedings of the 3rd International Symposium on Underground Freight Transportation by Capsule Pipelines and Other Tube/Tunnel Systems, Bochum, Germany, 19-20 September 2002.

16. Zhao, L.; Li, H. Location selection of intra-city distribution hubs in the metro-integrated logistics system. Tunn. Undergr. Space Technol. 2018, 80, 246-256. [CrossRef]

17. Hai, D.; Xu, J.; Duan, Z.; Chen, C. Effects of underground logistics system on urban freight traffic: A case study in Shanghai, China. J. Clean. Prod. 2020, 121019. [CrossRef] 
18. Chen, Z.; Dong, J.; Ren, R. Urban underground logistics system in China: Opportunities or challenges? Undergr. Space 2017, 2, 195-208. [CrossRef]

19. Heijden, M.C.V.D.; Harten, A.V.; Ebben, M.J.R. Using Simulation to Design an Automated Underground System for Transporting Freight Around Schiphol Airport. INTERFACES 2002, 32, 1-19. [CrossRef]

20. Fan, Y.; Liang, C.; Hu, X.; Li, Y. Planning Connections Between Underground Logistics System and Container Ports. Comput. Ind. Eng. 2019, 139, 1-10. [CrossRef]

21. Gao, Y.; Chang, D.; Fang, T.; Luo, T. Design and optimization of parking lot in an underground container logistics system. Comput. Ind. Eng. 2019, 130, 327-337. [CrossRef]

22. Pan, Y.; Liang, C.; Dong, L. A two-stage model for an urban underground container transportation plan problem. Comput. Ind. Eng. 2019, 138, 106-113. [CrossRef]

23. Chen, Y.; Liu, Y.; Guo, D.; Chen, Z.; Li, X. Freight Transit Assignments for an Integrated Network of Road Transportation and Underground Logistics Systems. J. Pipeline Syst. Eng. Pract. 2020, 11, 04020014. [CrossRef]

24. Stein, D.; Schoesser, B. Cargo Cap-Transportation of goods through underground pipelines: Research project in Germany. New Pipeline Technol. Secur. Saf. 2003, 2, 1625-1634.

25. Zhong, Y.; Luo, S.; Bao, M.; Lv, X. Dynamic Network Planning of Underground Logistics System on Uncertainty Graph. Math. Probl. Eng. 2019, 4,1-13. [CrossRef]

26. Zhou, A.; Zhou, A. Urban underground logistics node location. J. Chang. Univ. Sci. Technol. (Nat. Sci.) 2017, 14, 48-53.

27. Yan, W.; Qin, Y. Research on Bi-level programming model and algorithm of underground logistics node location. Chin. J. Undergr. Space Eng. 2016, 12, 870-874.

28. Li, T.; Wang, Z. Optimization Layout of Undergroud Logistics Network in big Cities with Plant Growth Simulation Algorithm. Syst. Eng.-Theory Pract. 2013, 33, 971-980.

29. Li, D.; Zhao, L.; Wang, C.; Sun, W. Selection of China's imported grain distribution centers in the context of the Belt and Road initiative. Transp. Res. Part E 2018, 120, 16-34. [CrossRef]

30. He, M.; Sun, L.; Zeng, X.; Liu, W.; Tao, S. Node layout plans for urban underground logistics systems based on heuristic Bat algorithm. Comput. Commun. 2020, 154, 465-480. [CrossRef]

31. Fu, P.; Yin, H. Logistics Enterprise Evaluation Model Based on Fuzzy Clustering Analysis. Phys. Procedia 2012, 24, 1583-1587. [CrossRef]

32. Wu, Q.; Chen, F.; Huang, Y.; Hu, Y. Calculation and Analysis of Traffic Congestion Cost in Beijing. J. Transp. Syst. Eng. Inf. Technol. 2011, 11, 168-172.

33. Yang, L.; Zheng, B.; Zhang, Y. Study on Cargo Transport Time Cost. Value Eng. 2015, 34, 189-190.

Publisher's Note: MDPI stays neutral with regard to jurisdictional claims in published maps and institutional affiliations.

(C) 2020 by the authors. Licensee MDPI, Basel, Switzerland. This article is an open access article distributed under the terms and conditions of the Creative Commons Attribution (CC BY) license (http://creativecommons.org/licenses/by/4.0/). 